\title{
Impact des vaccins dans les pays à bas et hauts revenus
}

\author{
Leif Gothefors \\ Département de Sciences Cliniques/Pédiatrie, Université d'Umeå, Umeå, Suède
}

\section{Mots-clés}

Vaccins $\cdot$ Vaccination, programme étendu

\section{Résumé}

La vaccination est devenue la mesure de santé publique la plus efficace pour le contrôle des maladies infectieuses, après l'accès à de l'eau potable non contaminée. L'histoire de la vaccination est marquée par de grands espoirs et quelques déceptions. La seconde moitié du $20^{\text {ème }}$ siècle a été notamment témoin du développement de remarquables projets de vaccination. II sera possible d'éradiquer la poliomyélite et la rougeole dans quelques années, mais près de 3 millions de personnes, habituellement des enfants âgés de moins de 5 ans, décèdent chaque année de maladies pouvant être prévenues par des vaccins. Les pays en développement luttent pour obtenir les vaccins dont leurs enfants ont désespérément besoin. Pourtant, en Europe et en Amérique du Nord, des personnes ont fait preuve d'une certaine inconscience à propos des vaccins: «ces maladies ne sont plus une menace, les vaccins sont plus dangereux que ces maladies». Ces conceptions erronées ont été à l'origine d'épidémies de rougeole, de diphtérie et de coqueluche. La communauté internationale doit continuer à consacrer les ressources nécessaires, le financement et le travail humain afin d'exploiter totalement les promesses de soulagement de la misère humaine qu'offrent les vaccins.

Copyright $\odot 2008$ Nestec Ltd., Vevey/S. Karger AG, Basel

En 2007, le British Medical Journal a demandé à ses lecteurs de citer les progrès médicaux les plus importants depuis 1840 [1]. Ce sondage, qui n'était pas réellement (c) 2008 Nestec Ltd. Vevey/S. Karger AG, Basel 0250-9644/08/0662-0055\$24.50/0

ax +4161306 1234

E-Mail karger@karger.ch

www.karger.com
Accessible en ligne à: www.karger.com/anf scientifique, a produit un quatuor de tête: équipement sanitaire (eau non contaminée et tout-à-l'égout), antibiotiques, anesthésie et vaccins. Si le vote devait se fonder sur le nombre de vies sauvées, les vaccins semblent difficiles à battre (tableau 1).

L'éradication réussie de la variole en 1977 a abouti à un optimisme compréhensible quant à la possibilité d'éradiquer d'autres maladies infectieuses par la vaccination. En 1974, l'OMS a créé le programme élargi de vaccination (PEV) afin de fournir les vaccins de base aux enfants du monde entier. À cette époque, moins de 5\% des enfants étaient vaccinés contre les six maladies cibles (tuberculose, diphtérie, tétanos, coqueluche, poliomyélite et rougeole). De plus, les programmes de vaccination étaient essentiellement limités aux pays industrialisés et n'étaient que partiellement mis en œuvre. Malgré les intentions de l'OMS (par les travaux du PEV) et la bonne disponibilité de vaccins peu coûteux, sûrs et efficaces, aucun autre agent pathogène n'a encore été globalement éradiqué. L'éradication de la poliomyélite et de la rougeole paraît cependant possible, et la plus grande partie du présent article sera donc consacrée à ces efforts. Nous traiterons uniquement des vaccins utilisés dans le cadre du PEV (actuellement ou dans un futur proche).

\section{Quelques définitions}

L'éradication est l'abolition permanente et mondiale d'une infection due à un agent spécifique. Les mesures d'intervention peuvent ainsi être arrêtées.

L'élimination est la réduction à zéro de l'incidence d'une maladie spécifiée dans une zone géographique dé- 
Tableau 1. Décès dus à des maladies contre lesquelles existent des vaccinations répandues, Australie 19262000

\begin{tabular}{lrrrrrr}
\hline Période & Diphtérie & Coqueluche & Tétanos & Poliomyélite & $\begin{array}{c}\text { Rougeole } \\
\text { en millions }\end{array}$ & $\begin{array}{c}\text { Population estimée } \\
\text { en }\end{array}$ \\
\hline $1926-1935$ & 4073 & 2808 & 879 & 430 & 1102 & 6,6 \\
$1936-1945$ & 2791 & 1693 & 655 & 618 & 822 & 7,2 \\
$1946-1955$ & 624 & 429 & 625 & 1013 & 495 & 8,6 \\
$1956-1965$ & 44 & 58 & 280 & 123 & 210 & 11 \\
$1966-1975$ & 11 & 22 & 82 & 2 & 146 & 13,7 \\
$1976-1985$ & 2 & 14 & 31 & 2 & 62 & 14,9 \\
$1986-1995$ & 2 & 9 & 21 & 0 & 32 & 17,3 \\
$1996-2000$ & 0 & 9 & 5 & 0 & 0 & 18,7
\end{tabular}

Les chiffres en italiques correspondent à la décennie où la vaccination a débuté pour la maladie indiquée.

Reproduit avec l'autorisation du NSW Public Health Bulletin [2].

finie: les mesures d'intervention doivent être maintenues car il existe une possibilité de réintroduction de la maladie à partir d'autres zones.

Une maladie peut être mise sous contrôle: réduction de l'incidence, de la morbidité ou de la mortalité à un taux localement accepté; le maintien des mesures d'intervention est cependant nécessaire afin de maintenir cette réduction.

\section{Variole}

Tout au long du $19^{\text {ème }}$ siècle, la plupart des pays industrialisés ont introduit la vaccination contre la variole et, vers 1900, plusieurs pays nord-européens ont été libérés de cette maladie. La vaccination a été cependant poursuivie jusqu'aux années 1970 à titre de moyen protecteur en cas de réintroduction du virus.

En 1959, l'OMS a décidé d'entreprendre un programme global d'éradication. Des campagnes de vaccination de masse ont été introduites, mais leurs progrès ont été décevants, particulièrement en Afrique et dans le souscontinent indien. Des insuffisances en financement et en personnel (les équipes de l'OMS étaient, à cette époque, préoccupées par l'éradication du paludisme) peuvent avoir contribué à cet échec relatif. En 1966, la stratégie a été modifiée pour une politique de «surveillance et contention", également appelée "vaccination sur alarme», qui consistait à ériger une barrière de sujets immunisés autour du cas et de ses contacts [3]. Cette approche s'est avérée plus efficace et le dernier cas de variole d'origine naturelle a été diagnostiqué en Somalie en 1977. Par la suite, l'OMS a officiellement déclaré l'éradication de la variole au plan mondial en 1979. Dans cette situation, ne serait-il pas prudent de détruire les stocks connus de virus de la variole conservés en laboratoire, par exemple ceux du Centre for Disease Control et de l'Institut Vector à Novosibirsk? Plusieurs organisations scientifiques ont recommandé la destruction de ces virus [4], mais ce domaine est devenu politique au cours de la dernière décennie. L'Assemblée Mondiale de la Santé de 2007 a recommandé que les stocks de virus soient détruits (dans le futur) mais uniquement quand «les résultats de recherches capitales pour une amélioration de la réponse de santé publique à une épidémie le permettront» [5].

Au cours des années suivant le 11 septembre, la menace d'une attaque bioterroriste utilisant la variole à titre d'arme a incité les autorités américaines à réinstaurer temporairement la vaccination antivariolique en 2002 pour le personnel militaire et les civils à haut risque. Des études des événements indésirables probablement imputables au vaccin ont révélé 21 cas de cardite avec 3 décès dans une étude (37 901 civils) et 39 cas d'événements indésirables neurologiques graves dans une autre (665000 militaires et personnels civils) [6, 7]. La prévalence de ces événements dans la population étudiée a été cependant similaire à celle attendue dans la population générale. La politique de l'OMS est cependant opposée à ce type de vaccination antivariolique préventive et l'Institut de Médecine des États-Unis a critiqué le Centre for Disease Control pour ce programme, «résultat d'une décision politique extravagante consistant à vacciner des personnes contre une maladie qui n'existe pas avec un vaccin qui expose à certains risques bien connus» [8]. 


\section{Tuberculose}

Le rapport annuel «Global tuberculosis control 2007» [9] conclut que «l'incidence globale de la tuberculose a atteint un pic entre 2000 et 2005 ... L'épidémie globale de tuberculose est à présent sur le point de décliner». Aujourd'hui, le principal mécanisme pour l'atteinte de cet objectif est basé sur le succès de la stratégie DOTS (Traitement directement observé, court terme) introduite en 1995. Ce rapport ne cite jamais le vaccin bacille Calmette-Guérin (BCG), et la question est de savoir si ce vaccin a encore un futur.

Selon des estimations, environ un tiers de la population globale est infectée de façon asymptomatique par le bacille tuberculeux et environ $5-10 \%$ sont atteints de tuberculose clinique [10]. La tuberculose est directement responsable de plus d'un quart de l'ensemble des décès évitables. La plupart des nouveaux cas et décès surviennent dans des pays en développement, où des enfants sont souvent infectés.

Les pays industrialisés ont pu enregistrer une diminution de l'incidence de la tuberculose pendant un certain nombre d'années, mais cette tendance positive s'est modifiée vers la fin du 20 ème siècle. Cette situation est imputable à une immigration à partir de zones d'endémie, à des sujets positifs pour le VIH, à des toxicomanes et à des détenus [10].

Le vaccin BCG a été utilisé pour la première fois en 1921 (administration par voie orale chez des nourrissons [11]) et est l'un des vaccins les plus utilisés malgré des données conflictuelles quant à son efficacité protectrice. Il exerce un effet documenté (50-80\%) contre la méningite et la tuberculose disséminée chez l'enfant mais ne prévient pas la primo-infection ni, fait plus important, la réactivation d'une infection pulmonaire latente, qui est la principale source de dissémination de la bactérie dans la communauté. Cet échec, avec la pandémie croissante de $\mathrm{VIH} /$ sida et l'apparition de mycobactéries multirésistantes, menace d'annihiler les effets des stratégies actuelles de contrôle de la tuberculose.

Dans les pays où la charge pathologique due à la tuberculose est élevée, une dose de BCG doit être administrée à tous les nourrissons dès que possible après la naissance. Les exceptions sont les enfants infectés de façon connue par le VIH [12]. Dans les zones où la charge due à la tuberculose est basse, le BCG est uniquement administré aux groupes à risque de contracter cette maladie, ou est totalement remplacé par une détection des cas et un traitement précoce. La vaccination des adultes et les vaccinations réitérées ne sont pas recommandées par l'OMS [10].
Le vaccin BCG demeure l'un des trois facteurs sur lesquels repose le contrôle de la tuberculose, avec un diagnostic précoce et un traitement adéquat et un traçage des sujets contacts. Il existe un besoin urgent d'un vaccin plus efficace qui pourrait également prévenir la réactivation de la bactérie.

\section{Diphtérie}

La diphtérie a été l'une des maladies infantiles les plus redoutées, se caractérisant par des épidémies dévastatrices. La plupart des infections par Corynebacterium diphtheriae ont heureusement une évolution clinique bénigne ou sont totalement asymptomatiques, mais la mortalité a atteint $50 \%$ au cours d'une épidémie majeure en Europe et aux États-Unis dans les années 1880. La mortalité a diminué à environ $15 \%$ au cours de la première guerre mondiale (principalement en raison de l'administration de l'antitoxine) mais peut encore atteindre, malgré le traitement moderne, $10 \%$ dans des zones d'endémie $[13,14]$. Des estimations indiquent que, avant que le vaccin ne soit facilement disponible, il se produisait environ 1 million de cas de diphtérie, résultant en 50 000-60 000 décès, chaque année dans les pays en développement [13]. Le vaccin a été inclus dans le PEV en 1974 et, très probablement en conséquence, le nombre global de cas rapportés de diphtérie a diminué de plus de 90\% (fig. 1) de 1980 à 2000.

Dans certains pays, particulièrement en Afrique subsaharienne mais également dans certaines zones d'Amérique du Sud et d'Asie de l'Est, la couverture vaccinale par 3 doses de vaccin antidiphtérique (administré sous forme de vaccin diphtérie/tétanos/coqueluche à cellules entières, DTCce) est de moins de $50 \%$ de la population des nouveau-nés [13]. Dans ces pays, où la diphtérie est encore endémique, la morbidité et la mortalité dues à cette maladie demeurent élevées, et ce sont les enfants d'âge préscolaire et scolaire qui sont le plus souvent atteints.

Dans la plupart des pays industrialisés, où la couverture vaccinale est élevée, la diphtérie endémique a disparu ou est extrêmement rare, mais des épidémies surviennent encore. Des études sérologiques menées au cours des années 1980 ont indiqué que, même en Europe et aux États-Unis où la couverture vaccinale était élevée, une importante proportion de la population adulte, allant souvent jusqu'à $50 \%$, était sensible à la diphtérie [15]. Deux importantes raisons sont les suivantes: 1) l'immunisation induite par le vaccin disparaît au cours du temps tant que des rappels périodiques ne sont pas effectués et 
Fig. 1. Incidence globale annuelle rapportée de la diphtérie et couverture par DTP3, 1980-2006. Reproduit avec l'autorisation de l'OMS.

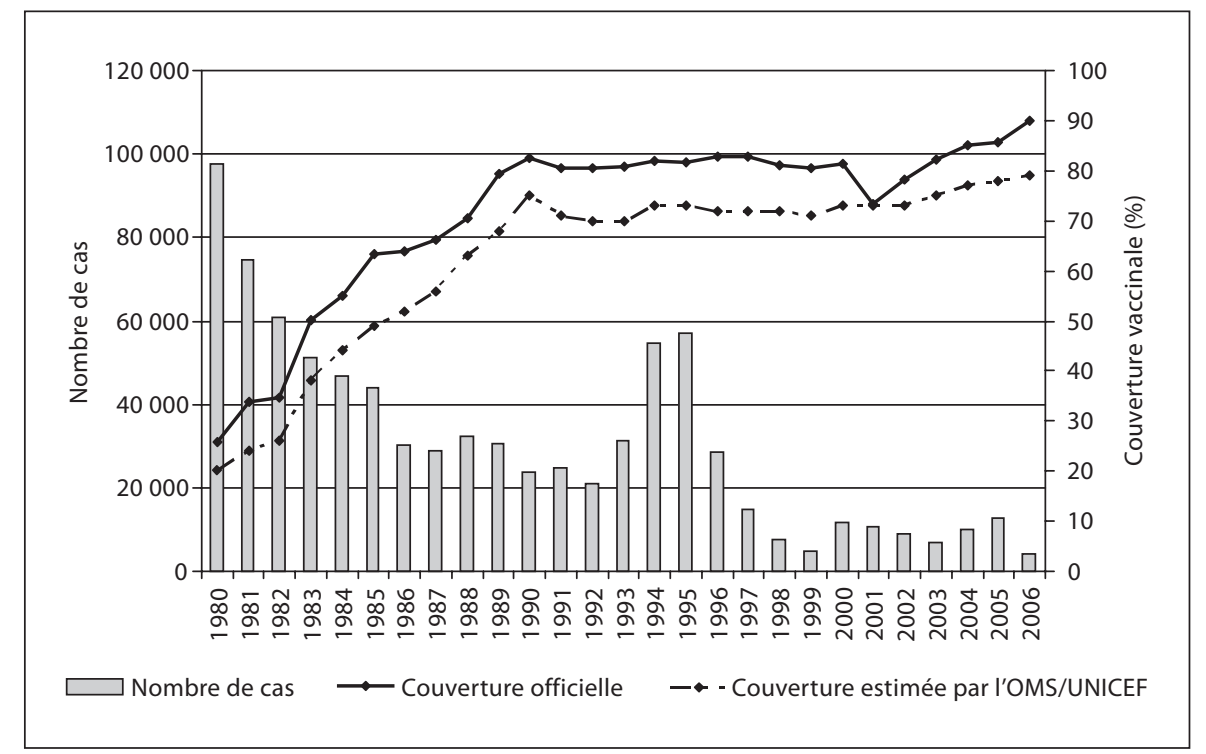

2) la circulation «normale» de $C$. diphtheriae toxinogène est réduite par la large utilisation du vaccin antidiphtérique et, de ce fait, l'effet naturel de rappel sur le système immunitaire est réduit [15].

Une épidémie serait possible si un nouveau biotype de C. diphtheriae apparaissait dans une situation où la couverture vaccinale serait basse chez les enfants et où il existerait d'importantes lacunes de l'immunité chez les adultes. La surpopulation domestique et une mauvaise hygiène personnelle sont également d'importants facteurs de risque. C'est probablement ce qui s'est passé dans la Fédération de Russie où la diphtérie est réapparue dans les années 1990, entraînant une épidémie qui s'est disséminée à tous les états nouvellement indépendants et les états baltes, causant plus de 157000 cas et 5000 décès. Près de $50 \%$ des décès sont survenus chez des adultes [14, 15]. Au moins jusqu'en 1986, la plupart de ces pays avaient une couverture vaccinale infantile raisonnablement élevée, avec une dose de rappel vers l'âge de 15 ans. L'immunogénicité du vaccin utilisé a été cependant mise en cause. La dissémination de l'épidémie aux nouveaux états indépendants a été facilitée par d'importants mouvements de populations. Cette situation pourrait se reproduire en raison des voyages internationaux sans cesse croissants aboutissant à l'introduction de souches toxinogènes dans des pays victimes d'une instabilité sociopolitique à l'origine de facteurs considérés comme importants pour la survenue d'épidémies, par exemple un grand nombre de réfugiés contraints de vivre dans des conditions hygiéniques et économiques extrême- ment difficiles et, fait important, une absence d'infrastructures facilitant la distribution du vaccin à ces personnes.

\section{Tétanos}

Le tétanos présente une originalité parmi les maladies prévenues par les vaccins du PEV: il n'est pas transmissible. Contrairement à la variole et à la poliomyélite, il ne peut être éradiqué. La mortalité élevée qu’il entraîne dans les pays industrialisés et en développement, habituellement associée à des blessures chez des personnes en bonne santé par ailleurs, particulièrement au cours des conflits militaires, rendait un vaccin souhaitable. Le vaccin toxoïde a été développé au cours des années 1920. Une vaccination efficace au cours de la seconde guerre mondiale a divisé par environ 30 l'incidence des cas de tétanos par rapport à celle rapportée au cours de la première guerre mondiale [16]. Dans la plupart des pays industrialisés, le tétanos est aujourd'hui considéré comme rare en raison de l'amélioration des soins des plaies et d'une couverture vaccinale élevée. La répartition actuelle des cas traduit une couverture vaccinale incomplète et, de ce fait, la plupart des cas surviennent chez des personnes âgées.

Dans les pays en développement, le poids pathologique du tétanos pèse cependant largement sur les nouveau-nés. À part cette tranche d'âge, la plupart des cas surviennent chez des garçons et de jeunes adultes non vaccinés, tandis 
Fig. 2. Incidence annuelle globale rapportée du tétanos néonatal et couverture vaccinale TT2+ (au moins 2 doses de toxoïde tétanique), 1980-2006. Reproduit avec l'autorisation de l'OMS.

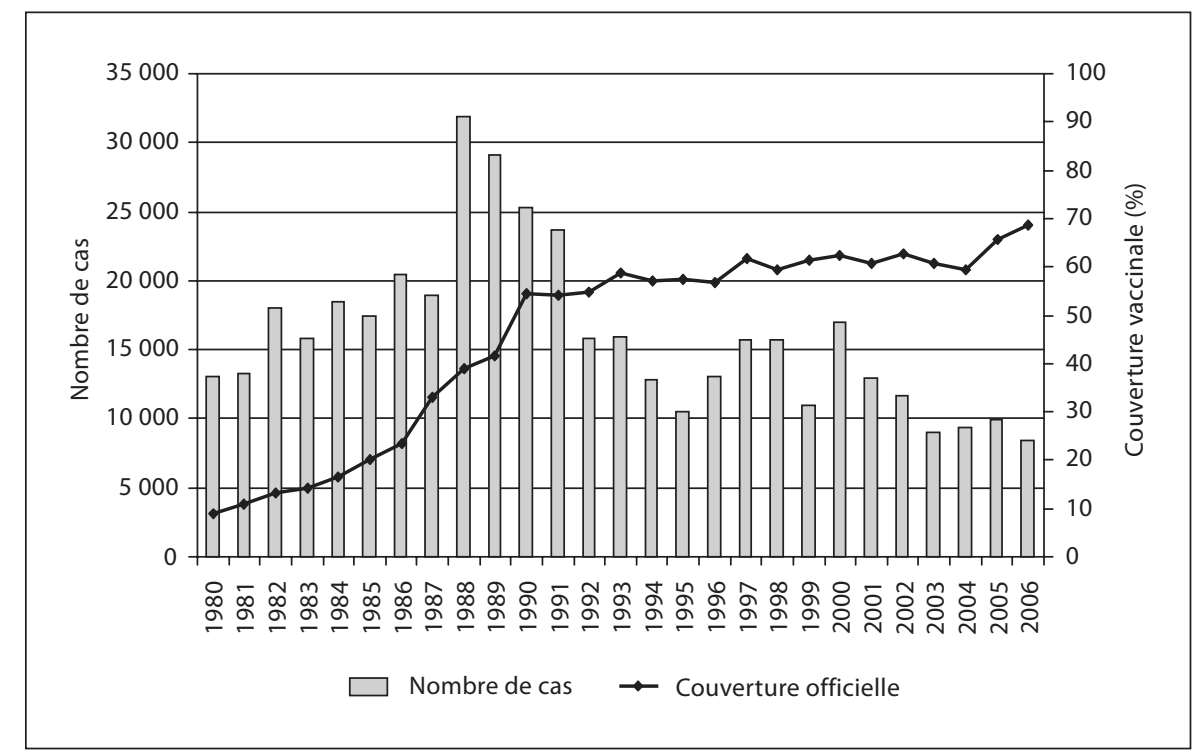

que l'incidence du tétanos diminue quand des programmes de vaccination sont en place. En 1980, des estimations basées sur des enquêtes de mortalité ont suggéré que le nombre de décès annuels par tétanos néonatal était voisin d'un million [17], et de 122 000-300 000 par tétanos non néonatal. En 1989, l’Assemblée mondiale de la Santé a appelé à l'élimination du tétanos néonatal (et maternel) vers 1995. La date cible a été depuis différée plusieurs fois. Des progrès ont cependant été réalisés (fig. 2): le nombre de décès au cours de l'année 2000 a été estimé à 200000 et, en septembre 2007, seuls 47 pays n'avaient pas encore éliminé le tétanos maternel et néonatal. Diverses stratégies sont appliquées pour atteindre cet objectif [18]: 1) vaccination des femmes enceintes au cours de leurs visites prénatales, 2) vaccination de toutes les femmes aptes à procréer au moyen d'actions supplémentaires de vaccination dans les zones où les femmes n'ont que peu ou pas d'accès à une vaccination systématique et, enfin, 3) promotion de soins expérimentés pour les accouchements.

\section{Coqueluche}

La coqueluche était l'une des maladies infantiles les plus fréquentes. Elle demeure la plus mal contrôlée des maladies infectieuses pédiatriques contre lesquelles existe un vaccin efficace administré à la plupart des nourrissons [19]. L'incidence de la coqueluche a cependant spectaculairement diminué (>90\%) sous l'effet de programmes intensifs de vaccination dans les pays industrialisés à partir des années 1950, et les épidémies majeures ont été largement éliminées.

Le vaccin (sous forme de DTC à cellules entières) fait partie du PEV depuis le début du programme en 1974. Depuis la fin des années 1980, environ 80\% des nourrissons au plan mondial ont été vaccinés. En dépit de ces avancées, l'OMS a estimé que 17 millions de cas étaient survenus à l'échelon mondial en 2003 et qu'environ 279000 patients étaient décédés de la maladie [20]. Les estimations des incidences doivent être cependant interprétées avec prudence: la définition des cas et les performances des systèmes de surveillance varient fortement en fonction des pays.

L'OMS recommande que la primovaccination par DTC se compose de 3 injections administrées aux âges de 6,10 et 14 semaines. La plupart des pays ont adopté ce schéma, mais avec des modifications mineures. Dans de nombreux pays, une dose de rappel est administrée 1 à 6 ans plus tard. Dans les pays nordiques et en Italie, 3 doses sont administrées aux âges de 3, 5 et 11-12 mois.

La vaccination a exercé l'impact attendu chez les jeunes enfants, où l'infection est désormais rare. La protection conférée par la vaccination contre la coqueluche disparaît cependant au bout de 6-12 ans (de même que l'immunité après une infection naturelle) [20]. Probablement à cause de cela, un déplacement s'est produit vers les enfants d'âge scolaire et les jeunes adultes chez lesquels l'incidence de la coqueluche (symptomatique aussi bien qu'asymptomatique) est plus élevée: $12-21 \%$ des adultes présentant une toux persistante pendant plus de 2 semai- 
nes peuvent être atteints de coqueluche [20,21]. La transmission de l'infection à partir de ces réservoirs bactériens dans des tranches d'âge plus âgées à de très jeunes enfants non immunisés [22] a également entraîné un accroissement de l'incidence de la coqueluche infantile dans de nombreux pays industrialisés. Cette situation contraste fortement avec l'objectif du programme, qui est de réduire l'incidence et la sévérité de la maladie chez les jeunes enfants, et particulièrement chez les plus jeunes d'entre eux. Afin de protéger ces petits enfants, un grand nombre étant trop jeunes pour pouvoir être vaccinés, le caractère endémique de la coqueluche pourrait être réduit par un renforcement de l'immunité dans les tranches d'âge supérieures [22]. Cet objectif est accessible avec le vaccin anticoquelucheux acellulaire, et l'introduction d'une vaccination des adolescents est à présent discutée dans de nombreux pays industrialisés [19].

L'incidence croissante de la coqueluche chez les adolescents et les jeunes adultes n'a été jusqu'ici que rarement rapportée dans des pays en développement ou des pays industrialisés où la couverture vaccinale était faible. De fait, il existe très peu de documentation sur l'épidémiologie de la coqueluche en Afrique, en Asie et en Amérique Latine. Au Sénégal, la même tendance a été observée sur une période de 12 ans après l'introduction de la vaccination [23] et des études sérologiques menées par exemple à Taipei, en Israël et en Turquie ont indiqué que les grands enfants, les adolescents et même les adultes étaient exposés à un risque de coqueluche malgré un programme de vaccination par 4 doses [23].

Le vaccin anticoquelucheux à cellules entières produit sous forme de DTC par de nombreux fabricants également dans des pays en développement a eu une efficacité supérieure à $80 \%$. En raison d'un accroissement de l'incidence d'effets indésirables mineurs à la suite de la vaccination et de rares réactions indésirables neurologiques, l'acceptabilité du vaccin a diminué dans un certain nombre de pays industrialisés au cours des années 1970. Cette situation a motivé le développement du vaccin anticoquelucheux acellulaire qui devrait être efficace dans toutes les régions du monde, mais il est peu probable que son prix soit actuellement abordable pour la plupart des pays en développement [20]. La priorité absolue afin de contrôler la coqueluche est d'atteindre une couverture globale de $90 \%$ avec les 3 doses de primovaccination par DTC à cellules entières. Une amélioration de la surveillance est requise afin de mieux savoir si une résurgence de la coqueluche, particulièrement chez les adolescents et les jeunes adultes, survient également dans des pays en développement.

\section{Poliomyélite}

La paralysie infantile, appelée par la suite poliomyélite, était bien connue même avant le $20^{\text {ème }}$ siècle. A cette époque, la maladie était endémique, la plupart des infections survenant chez des enfants âgés de 6 mois à 4 ans chez lesquels une méningite non paralytique est la conséquence la plus fréquente de l'atteinte du système nerveux central. De mauvaises conditions sanitaires entraînaient une exposition constante au virus, qui accroissait une immunité naturelle et précoce dans la population. Les conditions sanitaires des populations se sont améliorées dans les pays industrialisés au cours de la fin du $19^{\mathrm{ème}}$ et du début du $20^{\text {ème }}$ siècle, et, paradoxalement, cette situation a très fortement accru la proportion des enfants et adultes exposés à un risque d'infection poliomyélitique paralytique en retardant l'exposition au virus de la première année de la vie aux années ultérieures [24].

De petites épidémies localisées de poliomyélite paralytique ont été observées en Scandinavie à la fin du $19^{\text {ème }}$ siècle. La première épidémie documentée en Suède est survenue en 1881 dans le comté de Vaesterbotten [25] et, au début du $20^{\text {ème }}$ siècle, la maladie est devenue une caractéristique annuelle dans le profil épidémiologique suédois. Aux États-Unis, la première épidémie (décrite) est survenue en 1894 [26].

Avec une amélioration supplémentaire des conditions sanitaires, les épidémies se sont accrues et ont atteint des proportions pandémiques en Europe, en Amérique du Nord, en Australie et en Nouvelle-Zélande au cours de la première moitié du $20^{\text {ème }}$ siècle. Vers 1950 , l'incidence maximale de la poliomyélite paralytique aux États-Unis s'est décalée, passant des nourrissons aux enfants âgés de 5-9 ans, âge où le risque de paralysie est plus élevé [27]. L'épidémie de poliomyélite de 1952 est devenue la pire épidémie de l'histoire des États-Unis, avec plus de 3000 décès et 20000 personnes atteintes d'une paralysie invalidante [28].

En 1907, le pédiatre suédois Ivar Wickman [29] a classé les différents types cliniques de poliomyélite et a suspecté qu'il s'agissait d'une maladie infectieuse. Sa théorie a été renforcée par Landsteiner (Prix Nobel 1930, mais pour les groupes sanguins) qui avait infecté des singes au moyen d'un matériel provenant de moelle épinière d'enfants décédés de la maladie. Les 3 types ont été finalement identifiés en 1931 [26].

En 1948, année de la fondation de l'OMS, Ender, Weller et Robbins (Prix Nobel 1954) sont parvenus à cultiver le virus sur des tissus non nerveux. Se basant partiellement sur leurs résultats, les Docteurs Jonas Salk et Albert 
Sabin ont développé leurs vaccins contre la poliomyélite: un vaccin injectable inactivé (tué) (IPV) et un vaccin oral (vivant) (OPV). Salk a testé son vaccin lors de l'un des premiers essais contrôlés en double insu contre placebo au monde [30]. Après un certain nombre d'années, son vaccin, malgré «l'incident Cutter» [31] où le vaccin produit par le laboratoire de ce nom n'avait pas été totalement inactivé et avait provoqué près de 200 cas de poliomyélite, s'est avéré efficace pour l'obtention d'une forte réduction du nombre de cas de poliomyélite, tout d'abord aux ÉtatsUnis (1955) puis dans de nombreux autres pays. Peu après la présentation de son vaccin par Salk, des chercheurs suédois [32] ont présenté leurs propres vaccins, tués et plus sûrs, mais l'incident Cutter a malheureusement retardé de plusieurs années leur utilisation.

Le vaccin Sabin a été testé au plan international par l'OMS en 1959 quand d'importants groupes l'ont reçu, par exemple en Russie, en Hollande, au Mexique, au Chili, en Suède et au Japon [33]. Il offre l'avantage d'une administration plus facile, d'un coût plus bas et d'un effet prévenant non seulement les complications de l'infection poliomyélitique mais également l'infection intestinale initiale. Il est rapidement devenu le vaccin de choix pour la plupart des programmes nationaux de vaccination dans le monde. Quelques pays européens, par exemple la Hollande et certains pays scandinaves, continuent cependant à utiliser l'IPV. La Suède a introduit l'IPV en 1957 et, dès 1963, la poliomyélite était quasiment éradiquée dans ce pays. Non seulement la maladie a disparu, mais la circulation silencieuse du virus dans la communauté s'est interrompue, et ce à la grande surprise des défenseurs de l'OPV qui soutenaient que ce vaccin conférait une protection immunitaire locale bien supérieure dans l'intestin, prévenant ainsi la dissémination du poliovirus sauvage.

D'importantes épidémies de poliomyélite ont été à l'origine de paniques tous les étés au cours des années 1940 et 1950 aux États-Unis et en Europe de l'Ouest. La Suède a été l'un des premiers pays frappés par l'infection et c'est également dans ce pays qu'ont été en registrées l'incidence et la mortalité les plus élevées. Avec l'introduction du vaccin, la poliomyélite a été finalement placée sous contrôle. Il a fallu un peu plus longtemps pour que la poliomyélite soit reconnue comme un problème majeur dans les pays en développement.

Au cours des années 1970, un grand nombre d'enquêtes sur les cas de claudication (recherchant une paralysie flaccide aiguë) ont démontré que la poliomyélite était également très répandue dans de nombreux pays en développement. Ces résultats ont abouti à l'introduction

Impact des vaccins dans les pays à bas et hauts revenus d'une vaccination en routine par l'OPV dans la plupart des programmes nationaux du PEV. En 1985, la Pan American Health Organization (PAHO) a débuté son initiative d'éradication de la poliomyélite du continent américain. Ce programme s'est avéré très efficace: le dernier cas indigène de poliomyélite est survenu au Pérou en 1991. Avant que la poliomyélite puisse être déclarée comme éradiquée dans une région, aucun cas ne doit être constaté pendant une durée de 3 ans. Les Amériques ont été ainsi certifiées exemptes de poliomyélite en 1994 [34]. Il est intéressant de noter que, depuis 1999, l'Amérique du Nord est revenue à l'utilisation de l'IPV en raison d'un risque de réversion du virus vaccinal vivant et de réapparition de sa propriété à induire une paralysie: poliomyélite paralytique d'origine vaccinale, conséquence inévitable de l'utilisation de l'OPV.

En 1988, le poliovirus était endémique dans plus de 125 pays, paralysant plus de 1000 enfants chaque jour [26]. Cette même année, les résultats déjà positifs du programme PAHO ont convaincu l'Assemblée mondiale de la Santé de voter une résolution d'éradication de la poliomyélite vers l'année 2000. Cette déclaration reposait largement sur la connaissance de la disponibilité de fonds auprès du Rotary International et de sa campagne lancée en 1987 afin de recueillir 120 millions de dollars américains pour combattre la poliomyélite. Au moment où le monde sera certifié exempt de poliomyélite, ces dons seront 5 fois plus importants [26].

Dans le cadre du PEV, l'OPV est habituellement administré en 4 doses avant le premier anniversaire de l'enfant. Vers 1990, près de $80 \%$ des enfants nés chaque année étaient vaccinés et l'incidence de la maladie avait substantiellement diminué (fig. 3).

Les Journées Nationales de Vaccination (JNV) ont été instaurées afin d'améliorer encore cette situation. Ces campagnes d'immunisation de masse visent à compléter, mais non à remplacer, la vaccination systématique. L'objectif est d'interrompre la circulation du poliovirus en assurant la vaccination de tout enfant âgé de moins de 5 ans par 2 doses d'OPV à un mois d'intervalle, quel que soit le statut vaccinal précédent. De cette façon, chaque enfant de la tranche d'âge la plus sensible est protégé contre la poliomyélite dans le même temps: le virus ne dispose d'aucun hôte chez lequel survivre. Des volontaires peuvent agir à titre de vaccinateurs après une formation minimale, un des exemples étant une JNV en Inde, où 2 millions de volontaires ont vacciné 134 millions d'enfants en une seule journée [26].

La Chine a été victime d'une importante épidémie en 1989-1990, avec 5000 cas chaque année, ce qui a abouti 
Fig. 3. Incidence globale annuelle rapportée de la poliomyélite et couverture par Pol3, 1980-2006. Reproduit avec l'autorisation de l'OMS.

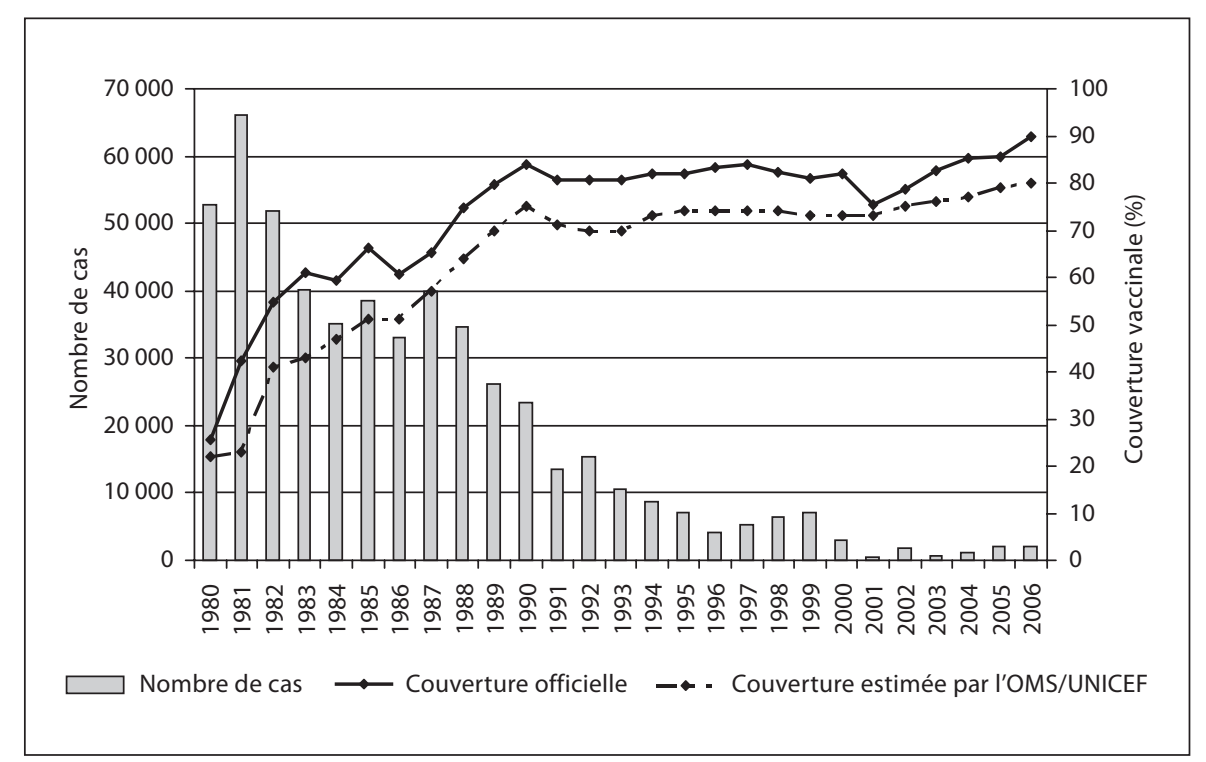

par la suite à des JNV en 1994, où 80 millions d'enfants ont été vaccinés sur une courte période [26]. Deux ans plus tard, le dernier cas de poliomyélite a été identifié en Chine. L'Inde a suivi l'exemple avec sa première JNV en 1995.

Les activités de la Région pacifique ouest de l'OMS ont abouti à la certification de la disparition de la poliomyélite dans celle-ci au cours de l'année 2000, le dernier cas ayant été observé au Cambodge en 1997. La Région pacifique ouest de l'OMS inclut la Chine ainsi que l'Indonésie avec plus d'un quart de la population globale totale [35].

Trois à cinq années de JNV répétées (dans les zones d'endémie 7-8 sessions par an) sont souvent nécessaires afin d'éradiquer la poliomyélite, mais une durée plus prolongée est indispensable dans certains pays, particulièrement ceux où la couverture due aux vaccinations de routine est basse. L'Inde et la Chine sont de bons exemples d'activités individuelles de pays. Le virus de la poliomyélite ne respecte cependant pas les frontières et, de ce fait, des pays voisins tentent de «synchroniser» leurs JNV. Cette approche a été appliquée en 1995 entre 19 pays d'Europe de l'Est et d'Asie centrale (opération MECACAR: Méditerranée, Caucase, Républiques asiatiques centrales et Russie) avec 56 millions d'enfants vaccinés [26]. Des campagnes multinationales similaires ont été menées en Afrique de l'Ouest et Centrale (au cours de l'an 2000, 76 millions d'enfants et en 2004, 63 millions) et le long de la frontière de l'Afghanistan et du Pakistan et d'autres zones de guerre et conflit où un cessez-le-feu avait été négocié pour les quelques jours des activités de vaccination [26].
En 2000, un nombre record de 550 millions d'enfants, soit près de $1 / 10$ de la population mondiale, a reçu l'OPV [26] et, la même année, 719 cas d'infections par le poliovirus sauvage sont survenus au plan mondial, signifiant une réduction de $99 \%$ depuis le début du programme en 1988 (tableau 2).

En Europe, les quelques 400 cas survenus au cours de l'année 1990 ont été réduits à seulement 200 en 1992. Cette même année, une épidémie de poliomyélite est survenue aux Pays-Bas (le virus étant arrivé d'Inde par l'intermédiaire du Moyen-Orient) dans un groupe qui refusait la vaccination pour des raisons religieuses et, ainsi, le virus de cette épidémie s'est disséminé au Canada [26]. De petites épidémies sont survenues en 1993 en Azerbaïdjan et en Ukraine et, en 1996, une épidémie est apparue en Albanie, pays qui avait été exempt de poliovirus sauvage pendant 18 ans, et s'est disséminée aux pays voisins [26]. Enfin, le dernier cas indigène de poliomyélite en Europe est survenu en Turquie en 1998 et, en 2002, la région européenne de l'OMS (51 pays) était certifiée comme affranchie de la poliomyélite [36].

La campagne pour l'éradication du virus de la poliomyélite a été manifestement très efficace mais ne s'est pas terminée en 2000 comme initialement prévu. Le moment de son achèvement a été plusieurs fois retardé.

Il existe plusieurs explications à ce retard: une infection par le poliovirus n'induit des troubles du système nerveux central que dans une faible proportion des sujets infectés, se traduisant en environ un cas par 100-200 infectés. En conséquence, il est difficile de suivre et de 
Tableau 2. Cas confirmés de poliomyélite dus au virus sauvages de 2000 à 2007 dans des pays où la maladie est endémique ou non [26]

\begin{tabular}{|c|c|c|c|c|c|c|c|c|}
\hline & 2000 & 2001 & 2002 & 2003 & 2004 & 2005 & 2006 & 2007 \\
\hline \multicolumn{9}{|c|}{ Cas dans les pays où la poliomyélite est actuellement endémique (novembre 2007) } \\
\hline Inde & 265 & 268 & 1600 & 225 & 134 & 66 & 676 & 873 \\
\hline Nigeria & 28 & 56 & 202 & 355 & 782 & 830 & 1122 & 285 \\
\hline Pakistan & 199 & 119 & 90 & 103 & 53 & 28 & 40 & 32 \\
\hline Afghanistan & 27 & 11 & 10 & 8 & 4 & 9 & 31 & 17 \\
\hline \multicolumn{9}{|c|}{ Total des cas dans les pays où la poliomyélite est endémique } \\
\hline & 702 & 475 & 1915 & 732 & 999 & 943 & 1869 & 1207 \\
\hline \multicolumn{9}{|c|}{ Total des cas dans les pays où la poliomyélite n'est pas endémique } \\
\hline & 17 & 8 & 3 & 52 & 256 & 1036 & 125 & 106 \\
\hline Pays, $\mathrm{n}$ & 23 & 15 & 9 & 15 & 18 & 16 & 17 & 12 \\
\hline Pays d'endémie, $\mathrm{n}$ & 20 & 10 & 7 & 6 & 6 & 6 & 4 & 4 \\
\hline
\end{tabular}

Données de l’OMS 21 mai 2008.

contrôler la dissémination massive du virus à partir de nombreuses infections intestinales habituellement silencieuses.

Les vaccins existants posent également certains problèmes: les deux vaccins doivent être administrés en plusieurs doses et les 3 types de poliovirus entrent en compétition mutuelle. Afin d'obtenir une multiplication efficace des 3 types, les vaccins doivent être administrés au moins 3 fois. D’autres virus entériques peuvent également entrer en compétition avec le virus vaccinal: le vaccin vivant peut poser des problèmes dans des zones où l'hygiène est médiocre. Un autre problème observé avec le vaccin vivant est la possibilité d'une réversion. Les poliovirus dérivés du vaccin (VDPV) peuvent 1 ) produire des épidémies de poliomyélite dans des zones où la couverture vaccinale par OPV est basse (cVDPV «circulants») et 2) se répliquer pendant plusieurs années chez des personnes immunodéficientes (iVDPV). Quand le virus vaccinal se dissémine entre de nombreuses personnes non immunisées et, dans l'intervalle, redevient un poliovirus sauvage, il peut provoquer une paralysie chez ces dernières. L'émergence de cVDPV peut être prévenue par une bonne couverture vaccinale. D'autre part, un iVDPV peut apparaitre chaque fois qu'une personne atteinte d'immunodéficience primaire est exposée à l'OPV. La seule façon de prévenir de nouvelles infections par iVDPV est de mettre fin à l'utilisation de l'OPV.

L'année 2003 paraissait prometteuse (tableau 2), et seuls 784 nouveaux cas ont été enregistrés, dont près de $50 \%$ au Nigeria. Malgré la poursuite d'efforts intensifs, il était dès lors évident que les derniers résidus de poliomyélite seraient difficiles à éliminer. Le nombre des pays où la poliomyélite est endémique est cependant désormais réduit à quatre: Afghanistan, Pakistan, Inde et Nigeria, et ces quatre pays se comportent comme source d'infection pour de nouvelles introductions dans des pays précédemment déclarés exempts de poliomyélite (fig. 4).

En août 2003, plusieurs états du nord du Nigeria ont suspendu des campagnes de vaccination antipoliomyélitique à la suite de préoccupations émises par certaines personnalités quant à la sécurité d'emploi de ce vaccin. Une nouvelle épidémie est survenue par la suite, originaire de l'état de Kano, réinfectant ainsi des zones précédemment exemptes de poliomyélite au Nigeria ainsi que 8 pays précédemment libérés de cette maladie en Afrique de l'Ouest et Centrale (tableau 2; fig. 4) [37]. Après la réintroduction de la vaccination au Nigeria du nord en juillet 2004, la campagne multinationale la plus importante jamais entreprise a été menée. Plus d'un million de vaccinateurs dans 23 pays d'Afrique de l'Ouest et Centrale y ont participé et plus de 80 millions d'enfants ont été vaccinés. Le nombre de cas a continué à augmenter au Nigeria mais, en 2007, une amélioration a semblé apparaître (tableau 2). Le Nigeria demeure l'obstacle unique et le plus important à l'objectif d'éradication de la poliomyélite [38]. Il y existe une importante transmission en raison de lacunes de l'immunité de la population et, dans plusieurs des états du nord, plus de $20 \%$ des enfants âgés de moins de 5 ans n'ont pas reçu une seule dose d'OPV [39].

Une importante épidémie est survenue en Inde en 2002, avec 1600 cas. Cependant, en 2005, après une augmentation spectaculaire de la qualité ainsi que de la quantité des campagnes de vaccination, l'Inde a pu faire état du plus faible nombre de cas jamais vu (66). L'Uttar Pra- 


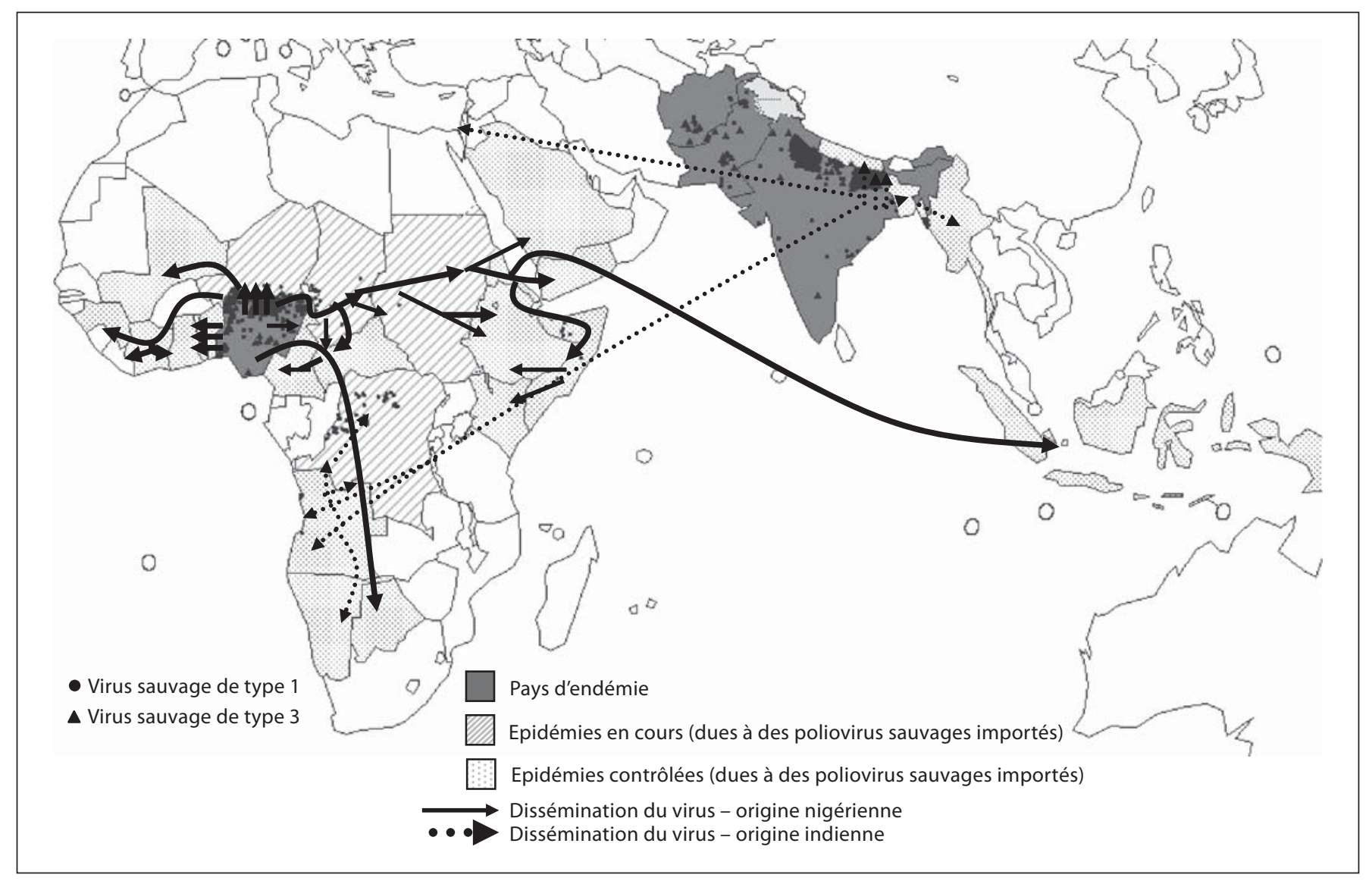

Fig. 4. Dissémination du poliovirus sauvage, 2003-2007 (à l'exclusion des virus détectés par surveillance environnementale et des virus dérivés du vaccin antipoliomyélitique). Pays d'endémie: au $1^{\mathrm{er}}$ janvier 2006, l'Égypte et le Niger ont été reclassés de zones d'endémie à zones de non endémie. Reproduit avec l'autorisation de l'OMS.

desh de l'ouest a été victime d'une épidémie en 2006, facilitée par une densité élevée de la population et de mauvaises conditions sanitaires. La prévalence élevée des affections entériques pourrait également interférer avec la réponse immunitaire et expliquer la faible efficacité de l'OPV comparativement à d'autres parties de l'Inde [38]. En conséquence, la plupart des enfants de l'Uttar Pradesh ont reçu plus de 12 doses de vaccin avant leur second anniversaire afin d'obtenir une immunité [39].

$\mathrm{Au}$ Pakistan, la transmission est limitée à des zones où la sécurité est compromise, et la situation est similaire en Afghanistan du Sud avec une épidémie importante en 2006. L'instabilité politique et les conflits armés rendent très difficiles les activités de vaccination dans les zones frontières entre les deux pays [38].

Les épidémies ont été interrompues avec succès dans la plupart des 24 pays en 2005 (à un coût de plus de 450 millions de dollars américains) (tableau 2). La plus im- portante épidémie survenue dans un pays unique ces dernières années, au Yémen et en Indonésie, n’a cependant pas été totalement abolie avant 2006.

Le poliovirus de type 2 n'a pas été isolé depuis 1999 et, en conséquence, des vaccins monovalents contenant le type 1 ou le type 3 sont aujourd'hui administrés. Des études ont montré que le mOPV1 monovalent est 3 fois plus efficace que l'OPV trivalent pour la protection des enfants contre la poliomyélite [37]. Ce vaccin a été utilisé avec succès dans des zones d'endémie telles l'Uttar Pradesh. De même, le mOPV3 a été utilisé dans des zones où le sérotype 3 domine.

En raison de ces épidémies étendues dans des pays précédemment exempts de poliomyélite en 2003-2006, un scepticisme s'est exprimé quant à la faisabilité d'une éradication. La poursuite d'un "contrôle effectif» (défini comme un maintien indéfini à $<500$ cas de poliomyélite/ an) serait peut-être moins coûteux et plus accessible [26]. 
Cependant, il existe aujourd'hui de nouveaux outils (test amélioré de diagnostic rapide et vaccins monovalents plus puissants) qui ont contribué à la réduction substantielle des cas de poliomyélite en 2007 (tableau 2). L'éradication totale est encore (2008) l'objectif. Le succès dépend des quatre pays restants, où des approches sur mesure pour chacun d'entre eux sont nécessaires en raison des différentes difficultés opérationnelles.

Si le monde est un jour certifié exempt de polio, que se passera-t-il? Le risque de résurgence demeure une réalité. L'importante proportion des infections infracliniques, qui facilitent une dissémination silencieuse du virus, constitue l'un des problèmes. Un autre problème est la possibilité susmentionnée d'une réversion du virus vaccinal vivant (OPV), provoquant une paralysie: un cas sur 3 millions de vaccinés et au moins 9 petites épidémies ont été rapportées (dues à des cVDPV), avec 200 nourrissons totalement paralysés [26]. Il sera critique de maintenir l'immunité des populations au long cours afin de prévenir la circulation de virus réémergents. En septembre 2006, le Comité Consultatif sur l'Eradication de la Poliomyélite a donné les recommandations suivantes pour l'arrêt éventuel des vaccinations systématiques par OPV [40]: 1) confirmation de l'interruption de la transmission du virus sauvage de la poliomyélite et contention de celuici; 2) utilisation d'un système de surveillance hautement sensible; 3) constitution d'un stock d'OPV monovalent afin de répondre à une réintroduction d'un poliovirus circulant; 4) maintien d'une couverture vaccinale $>90 \%$ par IPV dans tous les pays disposant de centres de vaccination contre le poliovirus; ces centres (qui pourraient assurer des fonctions essentielles de référence et de recherche) devraient être au nombre de moins de 20 au plan mondial; 5) arrêt global synchronisé de l'administration de l'OPV pour vaccination systématique et 6) confinement des souches de poliovirus Sabin.

Une campagne si prolongée serait toutefois coûteuse: 400 millions de dollars américains par an jusqu'à l'éradication du virus et plusieurs années par la suite. Néanmoins, cette tâche doit être terminée; le monde n'est qu'à quelques petits pas de se débarrasser définitivement de la poliomyélite.

\section{Rougeole}

L'infection par le virus de la rougeole vient en seconde place par rapport au paludisme en termes de nombre de personnes décédant chaque année à la suite de complications d'une maladie infectieuse [41].

Impact des vaccins dans les pays à bas et hauts revenus
Le premier texte sur la rougeole date du $10^{\text {ème }}$ siècle et a été rédigé par le médecin perse Rhazes. Pendant de nombreux siècles, on a alors supposé que la rougeole et la variole étaient étroitement apparentées: «Il faut redouter plus la rougeole que la variole» [42]. Au $17^{\text {ème }}$ siècle, une distinction a été effectuée entre les deux maladies et, en 1758, la nature infectieuse de la rougeole a été reconnue par Francis Home. L'épidémiologie a été beaucoup mieux comprise après l'épidémie des Iles Féroé en 1846 [42]. En 1954, Enders et Peebles parviennent à isoler le virus dans des cultures tissulaires et le vaccin est agréé en 1963.

La rougeole survient par cycles épidémiques et, dans les pays développés, débute habituellement dans de grandes villes, réservoirs où le virus demeure endémique, puis se dissémine aux zones rurales où la transmission s'éteint après une épidémie et où le virus doit être réintroduit pour que la prochaine saison épidémique puisse débuter.

Avant l'introduction du vaccin, le risque d'infection dans les pays développés était maximal chez les enfants d'âge scolaire. D'autre part, dans de nombreux pays en développement, l'infection survenait à un âge beaucoup plus jeune. En Afrique, 100\% des enfants âgés de 4 ans ont probablement été atteints de rougeole. Ici, les enfants sont exposés à l'ensemble de la communauté à un stade précoce (au moins comparativement aux enfants des pays industrialisés), et leur risque d'infection est élevé. De plus, leur immunité souvent non optimale, par exemple en raison d'une nutrition médiocre (vitamine A) et de la perte rapide des anticorps transférés par voie placentaire, explique pourquoi la rougeole frappe si précocement et souvent si sévèrement dans les pays en développement. Une surpopulation, aboutissant à des doses élevées de virus, peut également être importante [43].

Après l'introduction du vaccin, l'intervalle entre les épidémies a augmenté tandis que leur taille diminuait. Des cas relativement plus nombreux ont été également observés chez des enfants plus âgés qui n'avaient pas été vaccinés ou qui n'avaient pas répondu à la vaccination. Quand la couverture augmente tandis que la transmission virale diminue, même les sujets non vaccinés sont exposés à un risque d'infection plus faible. On a estimé que le seuil d'immunité de population était obtenu avec une couverture vaccinale de $93-95 \%$ [44]. Tant que cette immunité se maintiendra, la transmission du virus cessera progressivement et la rougeole sera éliminée. Pourtant, des cas de rougeole pourront être importés dans un pays à partir d'un autre où cette maladie est encore endémique. Dans une société bien immunisée toutefois, ces cas ne causeront que quelques cas secondaires. Quand la

Ann Nestlé [Fr] 2008;66:55-70 
Fig. 5. Incidence globale annuelle rapportée de la rougeole et couverture vaccinale contre celle-ci, 1980-2006. Reproduit avec l'autorisation de l'OMS.

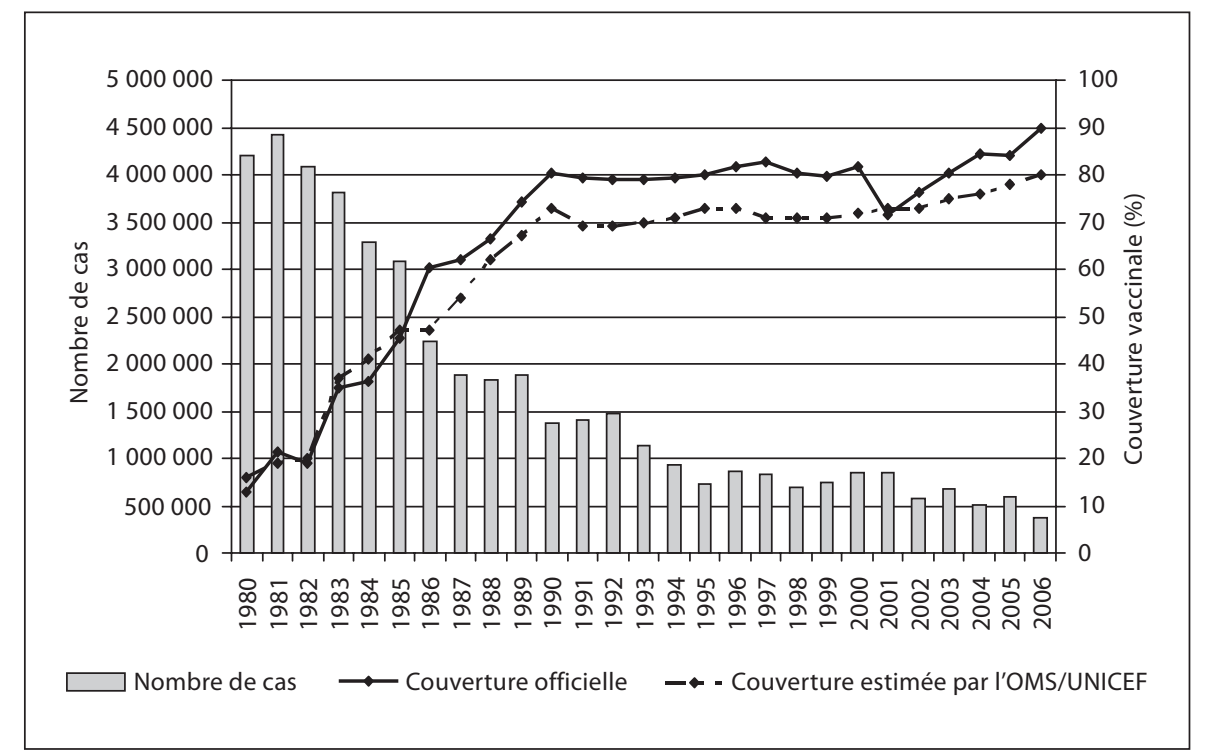

rougeole sera éliminée (simultanément) dans tous les pays, l'éradication sera globale.

Dans le monde occidental, une dose unique de vaccin administrée à l'âge de 12-18 mois induit une immunité chez environ $95 \%$ des vaccinés. Quand les $5 \%$ n'ayant pas répondu à la première dose en reçoivent une seconde, plus de $95 \%$ répondent et, de ce fait, avec une couverture vaccinale de $95 \%$ avec 2 doses, l'objectif d'immunité de population peut être atteint [41].

Pour les pays en développement, la vaccination a été recommandée dès l'âge de 9 mois en raison de la morbidité et de la mortalité infantiles élevées dues à la rougeole. À cet âge, une séroconversion ne survient que chez $85 \%$ des vaccinés [41]. Avec ce taux de conversion et une couverture de $90 \%$ (proportion plutôt optimiste pour de nombreux pays), seuls $77 \%$ des enfants seraient immunisés. Même une seconde dose à un âge où la séroconversion est de 95\%, administrée dans le cadre des services de santé de routine avec seulement $90 \%$ de couverture (ou moins), n'améliorerait pas fortement la situation concernant l'immunité de population. La réponse à ce problème pourrait être des campagnes de masse: si, au cours d'une campagne, $90 \%$ des enfants précédemment non vaccinés reçoivent la première dose et $90 \%$ de ceux précédemment vaccinés reçoivent la seconde, l'immunité de population sera plus élevée que les 95\% nécessaires [41, 45].

Le vaccin a été progressivement introduit dans le cadre du PEV à partir de 1974 dans la quasi-totalité des pays, avec la recommandation de l'OMS/UNICEF qu'une dose de vaccin soit administrée à l'âge de 9 mois chez au moins
$80 \%$ des enfants de chaque pays. Vers la fin des années 1980, la couverture globale était proche de $80 \%$ (fig. 5) mais, depuis lors, l'intérêt des donateurs a diminué et, de ce fait, la couverture a atteint un plateau à $70-80 \%$ au cours des années 1990. Le problème était non seulement qu'une faible couverture était associée à un nombre élevé de cas de rougeole mais encore, comme mentionné plus haut, que des enfants habituellement jeunes ont été infectés, avec une mortalité élevée. Comment pouvons-nous protéger ces jeunes enfants?

Les enfants peuvent-ils être vaccinés à un âge encore plus jeune? Afin de surmonter l'effet neutralisant des anticorps maternels, un vaccin antimorbilleux à titre élevé a été développé et administré à l'âge de 4-6 mois dans un certain nombre de pays africains. Ce vaccin a été plus immunogène que le vaccin standard et a protégé contre la rougeole dans cette tranche d'âge mais a été associé à une augmentation inattendue du nombre de décès (diarrhée, pneumonie et paludisme) chez les filles. Il n'est plus utilisé aujourd'hui [46].

La PAHO a développé une autre approche. Vers la fin du siècle, de nombreux pays industrialisés avaient suivi l'exemple de la Suède et de la Finlande et introduit une seconde dose en routine. En 1987, Cuba a réalisé une campagne nationale de vaccination de masse en une seule fois dans l'objectif de vacciner tous les enfants âgés de 9 mois à 14 ans, quels que soient leurs antécédents vaccinaux. L'idée était que la transmission devait diminuer chez les enfants plus âgés et qu'elle serait donc également évitée aux enfants plus jeunes. La stratégie, efficace à Cuba, a été 
introduite dans le reste des Amériques puis dans le restant du monde [47]. Elle se compose de 3 éléments: 1) maintien d'une couverture $>90 \%$ par vaccination systématique à l'âge de 9-12 mois dans chaque district, 2) réalisation d'une vaccination de masse en une seule fois chez tous les enfants âgés de 1-14 ans et 3) répétition des campagnes de masse tous les 3-5 ans chez tous les enfants âgés de 1-5 ans, quels que soient leurs antécédents pathologiques ou vaccinaux. Une surveillance efficace des cas de rougeole et une bonne prise en charge clinique des patients atteints de cette maladie sont, bien entendu, également importantes. Dans l'hémisphère occidental, cette stratégie a entraîné une diminution de plus de $99 \%$ des cas rapportés au cours des années 1990. En 2002, le Venezuela et la Colombie ont été les seuls pays connaissant d'importantes épidémies et, en septembre 2003, la PAHO a annoncé que l'hémisphère occidental avait été exempt de rougeole endémique pendant 10 mois consécutifs [41].

En 2002, la session spéciale de l'Assemblée Générale des Nations Unies sur l'enfance a fixé un objectif consistant à réduire la mortalité mondiale due à la rougeole de 50\% entre l'année 1999 et la fin de 2005. De récentes estimations modélisées indiquent qu'au cours de cette période, la diminution a été gratifiante (60\%), principalement grâce à des activités dans la région africaine [48]. Ces estimations sont confortées par des publications originaires de pays où les stratégies vaccinales recommandées ont été mises en œuvre. Une réduction de $92 \%$ des cas rapportés de rougeole a été observée dans 19 pays africains. Dans l'un des pays les plus pauvres du monde, le Malawi, le nombre de cas de rougeole est passé d'un nombre record de 7000 en 1997 à seulement 2 en 1999 [49]. Le Cambodge et le Vietnam ont fait état d'une diminution du nombre de cas de respectivement 12237 et 16512 à 264 et 410 au cours d'une période de 5 ans [48].

L'OMS, l'UNICEF et leurs partenaires ont maintenant une perspective pour la période 2006-2015: une couverture de $90 \%$ dans chaque district et une réduction de $90 \%$ de la mortalité mondiale due à la rougeole entre 2000 et 2010. De vastes pays comme l'Inde, le Pakistan et l'Indonésie ont encore une charge importante de cas de rougeole et de décès dus à cette maladie, et les activités décrites plus haut doivent y être totalement mises en œuvre $[48,49]$.

Dans les pays où une couverture vaccinale contre la rougeole a été atteinte, la seconde opportunité d'immunisation contre cette maladie peut être au contraire apportée par une vaccination systématique par 2 doses, la seconde étant administrée à l'âge de 12-18 mois ou à l'en-

Impact des vaccins dans les pays à bas et hauts revenus trée à l'école. Ce calendrier a été introduit par les pays les plus industrialisés, particulièrement après l'observation de résurgences de la rougeole. Cela s'est produit aux ÉtatsUnis de 1989 à 1991 avec plus de 50000 cas rapportés et 123 décès, et une faible couverture vaccinale a été la raison la plus importante de cette épidémie [41]. Au milieu des années 90, le Canada, avec un programme à une dose, a subi une épidémie de rougeole chez des enfants plus âgés et de jeunes adultes [41]. La couverture vaccinale était supérieure à $90 \%$ (mais n'atteignait pas 100\%) et la petite proportion d'enfants demeurés sensibles, en raison d'un échec de la primovaccination ou de la non-administration de la première dose, a ainsi augmenté au cours du temps. Quand le virus a été introduit, l'effectif de groupe était suffisamment important pour autoriser une transmission, et une épidémie est survenue. Des expériences provenant d'autres pays (Corée du Sud, Brésil et Sri Lanka) ont confirmé qu'une stratégie à dose unique ne pouvait prévenir des épidémies épisodiques de rougeole [41].

Des épidémies demeurent également fréquentes en Europe, bien que les décès soient désormais rares. En 2004, plus de 29000 cas ont été rapportés dans la région OMS Europe. La controverse sur la sécurité d'emploi du vaccin contre la rougeole à la fin des années 1990 a été à l'origine d'une diminution des vaccinations dans de nombreux pays. A Londres, jusqu'à $44 \%$ des enfants d'âge préscolaire ont été sensibles à un moment donné, suscitant la mise en œuvre de campagnes de vaccination. La couverture s'est améliorée mais est encore (au début de 2007) dangereusement faible, par exemple à Londres: $77 \%$ pour la première dose et $52 \%$ pour la seconde $[50,51]$. D’importantes épidémies s'observent au Royaume-Uni, se disséminant à d'autres pays européens. Autres exemples: en 2000, des épidémies ont eu lieu en Hollande et en Irlande avec respectivement 3300 et 1200 cas et, dans chaque pays, plus de 100 sujets hospitalisés et 2 ou 3 décès. En 2006, plus de 1000 cas sont survenus en Rhénanie-du-Nord-Westphalie (Allemagne); 15\% d'entre eux ont nécessité une hospitalisation [52].

Est-il possible d'éradiquer la rougeole? Ne serait-il pas plus économique de maintenir une couverture vaccinale élevée et d'éviter des décès dus à cette maladie? Les bénéfices seraient des économies concernant le traitement des patients atteints de rougeole et l'arrêt de la surveillance de cette maladie et de la vaccination contre celle-ci. Divers facteurs plaident cependant en faveur de l'éradication: 1) il n'existe aucun réservoir animal, 2) une excrétion chronique du virus (comme dans le cas de la poliomyélite, de l'herpès ou de l'hépatite virale) n’a pas été 
décrite, 3) de bons tests diagnostiques sont disponibles, 4) la vaccination est sûre et efficace et 5) il a été possible d'interrompre la transmission virale dans de vastes zones géographiques. Il existe cependant également des problèmes: l'augmentation de la densité de la population dans les zones métropolitaines nécessite une couverture élevée, la persistance des guerres et des actes de terrorisme s'oppose aux activités de vaccination et l'accroissement des voyages internationaux facilite la dissémination du virus. Même si la transmission du virus de la rougeole peut être interrompue au plan mondial, il existe encore la menace de sa réintroduction à partir d'accidents de laboratoire ou d'armes biologiques. Des auteurs ont également indiqué que la vaccination contre la rougeole réduisait globalement la mortalité infantile, non seulement par l'éradication de cette maladie mais également par une protection contre d'autres affections [53]. Nous devrons probablement continuer indéfiniment avec un calendrier à au moins une dose.

\section{Les autres vaccins du PEV}

L'OMS a recommandé l'inclusion des vaccins suivants dans le calendrier des vaccinations systématiques de l'enfant:

1988: vaccin contre la fièvre jaune dans les pays où le risque de contracter cette maladie est élevé

1992: vaccin anti-hépatite $B$, globalement

2006: vaccin anti-Haemophilus influenzae type b (Hib) globalement, «sauf si des données fiables démontrent une faible charge de cette maladie»

2006: un vaccin anti-pneumococcique conjugué «doit être envisagé pour inclusion dans les pays où les infections pneumococciques invasives sont considérées comme un problème de santé publique et où les sérotypes vaccinaux correspondent aux sérotypes locaux les plus importants».

\section{Fièvre jaune}

La fièvre jaune, maladie épidémique naguère particulièrement redoutée, est sous contrôle depuis plus de 40 ans à la suite de campagnes de vaccination de masse. Toutefois, depuis la fin des années 1980, cette maladie a réapparu avec des forces nouvelles en Afrique sub-saharienne et en Amérique du Sud et Centrale. Habituellement, elle provoque des cas sporadiques ou de petites épidémies mais, tandis que le moustique vecteur revient dans des villes où il avait été éradiqué, il existe également un risque de forme dévastatrice d'épidémies urbaines. Des vecteurs adéquats existent également en Asie. Des campagnes de vaccination de masse complètent actuellement la vaccination systématique des jeunes enfants [54].

\section{Hépatite $B$}

Trois cent cinquante millions de personnes sont des porteurs chroniques du virus et $500000-700000$ décèdent chaque année d'une atteinte hépatique (cirrhose ou cancer) [55]. Le vaccin, disponible depuis 1982 est «le premier vaccin dirigé contre un cancer humain majeur» et est très sûr; il induit une protection chez environ $95 \%$ des personnes en bonne santé, particulièrement chez les nourrissons et les enfants. Quatre-vingt-cinq pour-cent de l'ensemble des pays ont inclus ce vaccin dans leurs programmes et plus d'un milliard de doses ont été administrées. La prévalence de l'infection par le virus de l'hépatite $\mathrm{B}(\mathrm{VHB})$ et de l'état de porteur chronique de celui-ci a été efficacement réduite. Un exemple: le taux de porteurs chroniques chez les enfants de Taïwan a diminué de $9,8 \%$ avant le programme de vaccination anti-hépatite B (1984) à $0,7 \% 15$ ans après celui-ci (1999). L'incidence du carcinome hépatocellulaire infantile a également diminué à Taïwan, mais seulement de 0,54 à 0,20 (par 100000 enfants) [56]. Le vaccin est très efficace dans la prévention de la transmission horizontale, mais la transmission maternelle ne peut être totalement interrompue par le programme actuel de vaccination contre l'hépatite B. L'absence d'injection d'immunoglobulines anti-hépatite $B$ aux nourrissons de mères hautement infectieuses est une cause importante de cet échec (relatif). Le coût des immunoglobulines peut être prohibitif pour de nombreux pays, mais celui du vaccin contre l'hépatite B (qui avait été introduit à un coût de 100 dollars américains par dose dans les pays industrialisés) est aujourd'hui similaire à celui des vaccins classiques du programme PEV, soit 0,25 dollar américain par dose.

\section{Haemophilus influenzae type $b$}

Au cours des années 1990, le vaccin anti-Hib a été introduit par les services de vaccination systématique des enfants dans la plupart des pays industrialisés, et les maladies dues au Hib (pneumonie et méningite) ont été pratiquement éliminées. En règle générale, une primovaccination par 3 doses est effectuée en même temps que le DTC. Au Royaume-Uni, un calendrier accéléré 2-3-4 mois a été utilisé. Malgré une bonne couverture vaccinale, les cas d'infections invasives ont augmenté en 19992002, indiquant la nécessité d'un rappel au cours de la seconde année de la vie [57].

Des pays en développement ont hésité à introduire ce vaccin en raison de son prix relativement élevé et des pro- 
blèmes de détermination de la charge pathologique due au Hib dans les zones où la surveillance est médiocre. Cependant, avec le soutien financier de la Global Alliance for Vaccines and Immunization (GAVI), plus de 20 pays en développement ont à présent entrepris d'introduire le vaccin. Des données provenant du Kenya, où le vaccin a été introduit en 2001, indiquent qu'il s'agit d'une intervention d'un excellent rapport coût-efficacité et que des économies supplémentaires pourraient être réalisées si le prix du vaccin diminuait à moins de $50 \%$ de ce qu'il est actuellement [58].

\section{Infections pneumococciques}

Selon des estimations, les infections pneumococciques (pneumonie et méningite) sont responsables du décès de 1,3 million d'enfants âgés de moins de 5 ans chaque année. La quasi-totalité de ces décès survient dans les pays les plus pauvres du monde. Il n'existe aujourd'hui (2008) qu'un seul vaccin agréé pour utilisation chez les nourrissons et les jeunes enfants; il s'agit d'un vaccin conjugué incluant les 7 sérotypes les plus fréquents aux États-Unis (des vaccins à 10 et 13 valences sont en cours de développement). Il a été introduit aux États-Unis en 2000 et a induit une diminution rapide du taux des infections invasives causées par les sérotypes vaccinaux chez les enfants vaccinés, mais également chez des enfants non vaccinés et des adultes, démontrant une immunité de population [59].

La GAVI ainsi que d'autres initiatives de partenariats publics-privés sont très actives pour la fourniture de vaccins antipneumococciques aux pays en développement. Leurs efforts sincères sont louables, mais des Ministères de la Santé sont conseillés, avant de décider d'introduire ces vaccins, d'envisager divers problèmes liés à leur utilisation. Un domaine de préoccupation est l'observation d'une augmentation des cas dus à des sérotypes non vaccinaux, et l'accroissement de la résistance aux antibiotiques qui a été décrit chez ces «souches de remplacement». La répartition des sérotypes varie également d'un pays à un autre: les sérotypes 1 et 5 regroupés paraissent responsables de $29 \%$ des infections pneumococciques invasives en Inde, mais le vaccin heptavalent ne les couvre pas [60].

\section{Epilogue}

La vaccinologie peut revendiquer être un domaine de la médecine moderne ayant abouti à un accroissement spectaculaire de l'espérance de vie au cours de ces deux derniers siècles, mais, comme cette brève présentation l'a montré, il existe encore divers problèmes à résoudre avant que les infections actuelles soient éliminées ou au moins placées sous contrôle.

Par les éminents travaux du PEV, le taux global de vaccination paraissait être de $80 \%$ en 1990 , mais a depuis atteint un plateau (ou a même diminué dans certains pays) avec une petite augmentation au cours des dernières années. Cette situation se traduit par une proportion de $15-25 \%$ d'enfants encore non vaccinés au plan mondial. La communauté internationale doit continuer à consacrer les ressources nécessaires pour atteindre ces enfants malchanceux. Il est peut-être plus important de renforcer les programmes de PEV nationaux ou, mieux encore, les systèmes nationaux de santé, afin d'obtenir une couverture élevée plutôt que d'introduire de nouveaux vaccins relativement coûteux dont la pertinence est parfois douteuse.

Le calendrier actuel de vaccination $(6,10$ et 14 semaines) a été conçu au début des années 1980 pour le DTCOPV. Avec une meilleure connaissance des réponses immunitaires et de l'importance de l'immunité de population, des calendriers plus optimaux pourraient être déterminés, au moins pour certains antigènes (Hib et pneumocoque). Si ces calendriers autorisaient l'administration d'un nombre plus faible de doses, ils seraient d'un grand intérêt pratique ainsi qu'économique. Le calendrier nordique de vaccination ( 3 et 5 mois en primovaccination plus rappel à 12 mois) pourrait peut-être être également appliqué aux pays en développement.

\section{Remerciements}

Les collègues suivants ont donné de précieux commentaires sur le manuscrit: Rashmi Rodriguez, Cecilia Young, Rose-Marie Carlsson, Bo Stensson et Hans K:son Blomquist.

Bibliographie 1 Medical milestones: poll results. BMJ, Jan 6, 2007. www.bmj.com/cgi/content/full/334/ suppl_1/DC3.

2 Burgess M: Immunisation: a public health success. NSW Public Health Bull 2003;14:1-5.

3 Henderson DA, Borio LL, Lane JM: Smallpox and vaccinia; in Plotkin SA, Orenstein WA (eds): Vaccines. Philadelphia, Saunders, 1999, pp 123-154.

4 WHO: Report of the Ad Hoc Committee on Orthopoxvirus Infections. Executive Board report EB/95/33, Oct 10, 1994.

5 World Health Assembly, item 12:2, Aug 18, 2007. www.who.int/gb/ebwha/pdf_files/ WHA60/A60_R1-en.pdf. 
6 Casey CG, Iskander JK, Roper MH, et al: Adverse events associated with smallpox vaccination in the United States, January-October 2003. JAMA 2005;294:2734-2743.

-7 Sejvar JJ, Labutta RJ, Chapman LE, et al: Neurologic adverse events associated with smallpox vaccination in the United States, 2002-2004. JAMA 2005;294:2744-2750.

8 Institute of Medicine/Committee on Smallpox Vaccination Program Implementation: The Smallpox Vaccination Programme: public health in an age of terrorism. March 3, 2005. www.nap.edu/catalog.php?record id $=11240$ \#toc.

9 Global tuberculosis control - surveillance, planning, financing. WHO report 2007. WHO/HTM/TB/2007.376. www.who.int/tb/ publications/global_report/2007/introduction/en/index.html.

$\checkmark 10$ BCG vaccine. WHO position paper. Wkly Epidemiol Rec 2004;79:27-38.

11 Weill-Halle B: Oral vaccination; in Rosenthal SR (ed): BCG Vaccination against Tuberculosis. Boston, Little, Brown, 1957, pp 175-182.

12 Safety of BCG vaccine to HIV infected children. Global Advisory Committee on Vaccine Safety. Wkly Epidemiol Rec 2007;82: $18-24$.

13 Diphtheria vaccine. WHO position paper. Wkly Epidemiol Rec 2006;81:24-32.

14 Wharton M, Vitek CR: Diphtheria toxoid; in Plotkin SA, Orenstein WA (eds): Vaccines. Philadelphia, Saunders, 1999, pp 211-228.

- 15 Mattos-Guaraldi AL, Moreira LO, Damasco PV, Hirata Junior R: Diphtheria remains a threat to health in the developing world - an overview. Mem Inst Oswaldo Cruz 2003;98: 987-993.

16 Long AP: Immunization to tetanus. Workshop on professional medical experiences in Japan and Korea 1950-53. Walter Reed Army Medical Center, April 29, 1954.

17 Wassilak SGF, Roper MH, Murphy TV, Orenstein WA: Tetanus toxoid; in Plotkin SA, Orenstein WA (eds): Vaccines. Philadelphia, Saunders, 1999, pp 745-781.

18 Maternal and neonatal tetanus (MNT) elimination: the initiative and challenges. www. who.int/immunization_monitoring/diseases/MNTE_initiative/en/index.html.

19 Plotkin S: Aims, scope and findings of the global pertussis initiative. Pediatr Infect Dis J 2005;24:S5-S6.

-20 Pertussis vaccines. WHO position paper. Wkly Epidemiol Rec 2005;80:31-39.

-21 Singh M, Lingappan K: Whooping cough. The current scene. Chest 2006;130:15471553.

22 Tan T, Plotkin S: Controlling pertussis: considerations for the future. Pediatr Infect Dis J 2005;24:S98.

-23 Tan T, Trindade E, Skowronski D: Epidemiology of pertussis. Pediatr Infect Dis J 2005; 24:S10-S18.
24 Robertson S: Module 6: Poliomyelitis. The Immunological Basis for Immunization Series. WHO/EPI/GEN/93.16. Geneva, WHO, 1993.

25 Axelsson P: The history of polio in Sweden - from infantile paralysis to polio vaccine. Sven Med Tidskr 2004;8:57-65.

26 www.polioeradication.org.

27 Melnick JL: Poliomyelitis; in Warren K (ed): Tropical and Geographical Medicine, ed 2. New York, McGraw-Hill, 1990, pp 558-576.

28 Zamula E: A new challenge for former polio patients. FDA Consumer 1991;25:21-25.

29 Cohen MJ, Kaufman SR, Reiner BD: Aping science - a critical analysis of research at the Yerkes Regional Primate Research Center. Persp Med Res 1995;5:21-22. www.curedisease.com/Faqspolio.html.

30 Francis T, Korns R, Voight R, et al: An Evaluation of the 1954 Poliomyelitis Vaccine Trials. Ann Arbor, University of Michigan, 1955.

31 Offit PA: The Cutter incident, 50 years later. N Engl J Med 2005;352:1411-1412.

32 Wesslén T, Lycke E, Gard S, Olin G: Inactivation of poliomyelitis virus by formaldehyde. Arch Gesamte Virusforsch 1957;7:125-135.

33 Pan American Health Organization: Proceedings of the 2nd International Conference on Live Poliovirus Vaccines. Washington, PAHO, 1960.

-34 International notes certification of poliomyelitis eradication - the Americas 1994. Morb Mortal Wkly Rep 1994;43:720-722.

35 General news. Major milestones reached in global eradication: Western Pacific region is certified polio-free. Health Educ Res 2001; 16:109.

36 European region of the World Health Organization. Europe achieves historic milestone as region is declared polio-free. Press release, June 21, 2002.

37 Progress towards poliomyelitis eradication in Nigeria, January 2005 to December 2006. Wkly Epidemiol Rec 2007;82:105-116.

38 Conclusions and recommendations of the Advisory Committee on Poliomyelitis Eradication, Geneva, 11-12 October, 2006. Wkly Epidemiol Rec 2006;81:453-464.

39 Pallansch MA, Sandhu HA: The eradication of polio - progress and challenges. N Engl J Med 2006;355:2508-2511.

40 Conclusions and recommendations of the Advisory Committee on Poliomyelitis Eradication, Geneva, 11-12 October, 2006. Wkly Epidemiol Rec 2006;81:465-468.

41 Meissner HC, Strebel PM, Orenstein WA: Measles vaccines and the potential for worldwide eradication of measles. Pediatrics 2004; 114:1065-1069.
42 Drutz JE: Measles: its history and its eventual eradication. Semin Pediatr Infect Dis 2001;12:315-322.

43 Strebel PM, Papania MJ, Halsey NA: Measles vaccine; in Plotkin SA, Orenstein WA (eds): Vaccines. Philadelphia, Saunders, 1999, pp 389-440.

-44 Cutts FT, Steinglass R: Should measles be eradicated? BMJ 1998;316:765-767.

45 Measles vaccine: WHO position paper. Wkly Epidemiol Rec 2004;79:130-142.

-46 Expanded Programme on Immunization. Safety of high-titre measles vaccines. Wkly Epidemiol Rec 1992;67:357-361.

47 Measles: mortality reduction and regional elimination. Strategic plan 2001-2005. $\mathrm{WHO} / \mathrm{V} \& \mathrm{~B} / 01.13$.

48 Wolfson LJ, Strebel PM, Gacic-Dobo M, et al: Has the 2005 measles mortality reduction goal been achieved? A natural history modelling study. Lancet 2007;369:191-200.

49 Davey S: Measles eradication still a long way off. Bull World Health Organ 2001;79:584585 .

50 NHS Immunisation Statistics England 2006-2007. www.ic.nhs.uk/statistics-anddata-collections/health-and-lifestyles/immunisation.

51 Ashmore J, Addiman S, Cordery R, Maguire $\mathrm{H}$ : Measles in North East and North Central London, England: a situation report. Euro Surveill 2007;12E070920.2. www.eurosurveillance.org/ew/2007/070920.asp\#2.

52 van Treeck U: Measles outbreak in Germany: over 1,000 cases now reported in Nordrhein Westfalen. www.eurosurveillance.org/ew/ 2006/060511.asp.

53 Shann F: A little bit of measles does you good. BMJ 1999;319:4-5.

54 www.who.int/csr/disease/yellowfev/global_ partnership/en/index.html.

55 www.path.org/vaccineresources/hepb-indepth.php.

56 Chang M, Chen TH, Hsu HM, et al: Prevention of hepatocellular carcinoma by universal vaccination against hepatitis $B$ virus: the effect and problems. Clin Cancer Res 2005; 11:7953-7957.

57 WHO position paper on Haemophilus influenzae type b conjugate vaccines. Wkly Epidemiol Rec 2006;47:445-452.

-58 Akumu AO, English M, Scott AG, Griffiths UK: Economic evaluation of delivering Haemophilus influenzae type $\mathrm{b}$ vaccine in routine immunization services in Kenya. Bull World Health Organ 2007;85:511-518.

59 Pneumococcal conjugate vaccine for childhood immunization - WHO position paper. Wkly Epidemiol Rec 2007;82:93-104.

60 Singh NK: Pneumococcal vaccine concerns: shape-shifters and beyond. Vaccine 2007;25: 5244-5245. 